\title{
Enhanced cell migration and apoptosis resistance may underlie the association between high SERPINE1 expression and poor outcome in head and neck carcinoma patients
}

\author{
Miguel Angel Pavón ${ }^{1,2, \#}$, Irene Arroyo-Solera ${ }^{1,2, \#}$, Marta Téllez-Gabriel ${ }^{1,2}$, \\ Xavier León ${ }^{2,3}$, David Virós ${ }^{4}$, Montserrat López ${ }^{3}$, Alberto Gallardo5, Maria \\ Virtudes Céspedes ${ }^{1,2}$, Isolda Casanova ${ }^{1,2}$, Antonio López-Pousa ${ }^{2,6}$, Maria Antonia \\ Mangues? ${ }^{7}$ Miquel Quer ${ }^{3}$, Agustí Barnadas ${ }^{6}$, Ramón Mangues ${ }^{1,2}$ \\ ${ }^{1}$ Grup d'Oncogènesi i Antitumorals, Institut d'Investigacions Biomèdiques Sant Pau (IIB-Sant Pau), Barcelona, Spain \\ ${ }^{2}$ Centro de Investigación Biomédica en Red en Bioingeniería, Biomateriales y Nanomecidicina (CIBER-BBN), Barcelona, Spain \\ ${ }^{3}$ Department of Otorrinolaryngology, Hospital de la Santa Creu i Sant Pau, Barcelona, Spain \\ ${ }^{4}$ Department of Otorrinolaryngology, Hospital Moises Broggi, Sant Joan Despí, Spain \\ ${ }^{5}$ Department of Pathology, Clínica Girona, Girona, Spain \\ ${ }^{6}$ Department of Medical Oncology, Hospital de la Santa Creu i Sant Pau, Barcelona, Spain \\ ${ }^{7}$ Department of Pharmacy, Hospital de la Santa Creu i Sant Pau, Barcelona, Spain \\ \#These authors contributed equally to this study \\ Correspondence to: \\ Ramón Mangues, e-mail: rmangues@santpau.cat
}

Keywords: HNSCC, SERPINE 1, prognosis, biomarker, AKT

Received: April 14, $2015 \quad$ Accepted: August 14, 2015

Published: August 24, 2015

\section{ABSTRACT}

High SERPINE1 expression is a common event in head and neck squamous cell carcinoma (HNSCC); however, whether it plays a role in determining clinical outcome remains still unknown. We studied SERPINE1 as a prognostic marker in two HNSCC patient cohorts. In a retrospective study $(n=80)$, high expression of SERPINE1 was associated with poor progression-free $(p=0.022)$ and cancer-specific $(p=0.040)$ survival. In a prospective study $(n=190)$, high SERPINE1 expression was associated with poor local recurrence-free $(p=0.022)$, progression-free $(p=0.002)$ and cancerspecific $(p=0.006)$ survival. SERPINE1 expression was identified as an independent risk factor for progression-free survival in patients treated with chemo-radiotherapy or radiotherapy $(p=0.043)$. In both patient cohorts, high SERPINE1 expression increased the risk of metastasis spread $(p=0.045 ; p=0.029)$. The association between SERPINE1 expression and survival was confirmed using the HNSCC cohort included in The Cancer Genome Atlas project $(n=507)$. Once again, patients showing high expression had a poorer survival $(p<0.001)$. SERPINE1 over-expression in HNSCC cells reduced cell proliferation and enhanced migration. It also protected cells from cisplatin-induced apoptosis, which was accompanied by PI3K/AKT pathway activation. Downregulation of SERPINE1 expression had the opposite effect.

We propose SERPINE1 expression as a prognostic marker that could be used to stratify HNSCC patients according to their risk of recurrence.

\section{INTRODUCTION}

Head and neck squamous cell carcinoma (HNSCC) is the sixth leading cancer in incidence worldwide $[1,2]$. New treatment strategies that combine surgery, radiation and chemotherapy have improved organ preservation and patient quality-of-life [3]. However, 5-year survival has not markedly changed in the last two decades due to the high rate of loco-regional relapse and the development of metastasis or secondary tumors $[1,4]$. Classical clinicopathological 
features are insufficient to predict clinical outcome or to identify patients that will benefit from standard treatment regimens. Therefore, the development of new predictive biomarkers could help to classify this heterogeneous group of tumors and improve treatment decision-making [5].

Extracellular matrix (ECM) remodeling is a frequent event during neoplastic transformation of epithelial cells and it is also associated with tumor malignancy, cell migration and invasion [6, 7]. The plasminogen activator (PA) system plays a central role in this process, in particular by regulating ECM proteolysis and degradation [8]. SERPINE1 (PAI-1) is the main regulator of the PA system, and it is also involved in signal transduction, tumor growth, invasion and metastasis [9]. It is the main inhibitor of the plasminogen activators tPA and uPA. Plasminogen activators (PA) stimulate the production of plasmin that in turn activates the fibrinolytic pathway and extracellular matrix degradation, leading to enhanced tumor cell migration $[10,11]$. In several tumor types, SERPINE1 expression is up-regulated and it has been described as a poor prognostic marker [9, 12]. Besides its prognostic value, SERPINE1 expression has been validated as a marker for therapy decision making in patients with node-negative breast cancer $[13,14]$.

Previous studies pointed out that SERPINE1 expression increases during malignant transformation of squamous mucosa [15-19]. Gene expression profiles in HNSCC show that SERPINE1 is commonly over-expressed in primary tumors and lymph node metastasis [20-25]. However, the prognostic value of SERPINE1 in patients with HNSCC is still unknown. Although some studies have suggested an association between high SERPINE1 expression and poor prognosis [16, 20, 26-28], other authors have not found evidences of such an association $[15,18,29$, 30]. Inconclusive data reported to date could be related to small sample sizes or short follow-up data, and differences in patient characteristics or in the endpoint used to measure clinical outcome. Larger studies in patients with an accurate and longer clinical follow-up are therefore still necessary to establish the prognostic value of SERPINE1 in HNSCC.

On this basis, we studied the prognostic value of SERPINE1 expression, analyzing a retrospective $(n=80)$ and a prospective $(n=190)$ cohorts of HNSCC patients. We analyzed SERPINE1 expression in a third patient cohort obtained from The Cancer Genome Atlas database $(n=507)$. We also analyzed the effect of SERPINE1 expression on proliferation, migration and apoptosis induction in HNSCC cell lines.

\section{RESULTS}

\section{High SERPINE1 protein expression is associated with a higher rate of metastasis development and poor clinical outcome}

A total of 80 paraffin-embedded pre-treatment tumor biopsies, obtained from locally advanced patients with 68 months of median follow-up, were included in the retrospective immunohistochemical analysis (Table 1). Tumor cells showed membrane and cytoplasmatic positivity for SERPINE1 (Supplementary files, Figure S1). Tumor-adjacent normal tissue and stromal tissue areas were negative or showed negligible staining (Supplementary files, Figure S1).

Twenty-nine biopsies showed high SERPINE1 immunostaining intensity (3), 25 showed intermediate intensity (2), and 26 displayed low or negative staining (1) (Figure 1A). The percentage of SERPINE1 positive cells was similar in all samples (80-95\%).

We observed a significant association between SERPINE1 immunostaining intensity and metastatic recurrences after treatment $(p=0.045)$ (Table 1$)$. The rate of metastatic recurrences after treatment in patients with high SERPINE1 staining was higher than in patients with moderate or low staining.

SERPINE1 staining intensity was significantly associated with progression-free survival (PFS) (Figure 1C) and cancer-specific survival (CSS) (Figure 1D). Patients bearing tumors with high SERPINE1 staining intensity (3) had a shorter progression-free (PFS) $(p=0.022)$ and cancer-specific survival (CSS) $(p=0.040)$ than patients with tumors showing intermediate (2) or low (1) staining. There was a trend towards association between SERPINE1 staining intensity and local recurrence-free survival (LRFS), but this did not reach significance $(p=0.108)$ (Figure 1B). Only one oropharyngeal tumor was HPV positive in this patient cohort and was classified in the high SERPINE1 expression group. After performing an analysis that excluded this case we found that patients with high SERPINE1 expression continue having a significantly shorter progression-free survival than low expressing patients $(p=0.015)$ (Supplementary files, Figure S2).

\section{High SERPINE1 mRNA expression increases the risk of metastases development and is associated with poor outcome}

Following the positive association found in the retrospective IHC study, we analyzed SERPINE1 mRNA expression in 190 tumor biopsies obtained from an independent cohort of HNSCC patients with 37 months of median follow-up (Table 2). We also analyzed SERPINE1 expression in 24 normal mucosa samples obtained from areas without visible lesions.

SERPINE1 expression was significantly higher in tumor tissue than in normal mucosa samples $(p<0.001)$ (Figure 2A). Classification and regression-tree analysis method (CART) was used to establish the best cutoff to distinguish two groups of patients depending on SERPINE1 mRNA tumor levels and their probability of relapse (SERPINE1-mRNA level $<$ or $>0.8$ ). One hundred and fourteen patients had tumors with a SERPINE1 expression above the established threshold 
Table 1: Characteristics of patients included in the retrospective study

\begin{tabular}{|c|c|c|c|c|}
\hline Variable & All patients $(n=80)$ & $\begin{array}{l}\text { High SERPINE1 }(+++) \\
(n=29)\end{array}$ & $\begin{array}{c}\text { Intermediate or Low } \\
\text { SERPINE1 }(-/+/++)(n=51)\end{array}$ & $P$ value $^{1}$ \\
\hline \multicolumn{5}{|l|}{ Sex } \\
\hline Men & 76 & 26 & 50 & 0.182 \\
\hline Women & 4 & 3 & 1 & \\
\hline \multicolumn{5}{|l|}{ Age (years) } \\
\hline$<60$ & 30 & 11 & 19 & 0.952 \\
\hline$>60$ & 50 & 18 & 32 & \\
\hline \multicolumn{5}{|l|}{ Tumor site } \\
\hline Oral cavity & 7 & 5 & 2 & 0.095 \\
\hline Oropharynx & 13 & 2 & 11 & \\
\hline Hypopharynx & 13 & 4 & 9 & \\
\hline Larynx & 47 & 18 & 29 & \\
\hline \multicolumn{5}{|l|}{ Tumor size (T) } \\
\hline $\mathrm{T} 2$ & 8 & 4 & 4 & 0.690 \\
\hline T3 & 51 & 18 & 33 & \\
\hline $\mathrm{T} 4$ & 21 & 7 & 14 & \\
\hline \multicolumn{5}{|l|}{ Node $(\mathbf{N})$} \\
\hline Positive & 44 & 19 & 25 & 0.157 \\
\hline Negative & 36 & 10 & 26 & \\
\hline \multicolumn{5}{|c|}{ Tumor differentiation } \\
\hline Well & 6 & 2 & 4 & 0.438 \\
\hline Moderate & 67 & 26 & 41 & \\
\hline Poor & 7 & 1 & 6 & \\
\hline \multicolumn{5}{|l|}{ Tobacco } \\
\hline Non-smoker & 4 & 2 & 2 & 0.560 \\
\hline$<20$ cigarette/day & 5 & 1 & 4 & \\
\hline$>20$ cigarette/day & 70 & 26 & 44 & \\
\hline Cigar or pipe & 1 & - & 1 & \\
\hline \multicolumn{5}{|l|}{ Alcohol } \\
\hline Non-drinker & 13 & 7 & 6 & 0.152 \\
\hline$<100$ gr./day & 32 & 10 & 22 & \\
\hline$>100$ gr./day & 35 & 12 & 23 & \\
\hline \multicolumn{5}{|l|}{ Local recurrence } \\
\hline Yes & 15 & 8 & 7 & 0.111 \\
\hline No & 65 & 21 & 44 & \\
\hline
\end{tabular}

(Continued) 


\begin{tabular}{|c|c|c|c|c|}
\hline Variable & All patients $(n=80)$ & $\begin{array}{l}\text { High SERPINE1 }(+++) \\
\qquad(n=29)\end{array}$ & $\begin{array}{c}\text { Intermediate or Low } \\
\text { SERPINE1 }(-/+/++)(n=\mathbf{5 1})\end{array}$ & $P$ value ${ }^{1}$ \\
\hline \multicolumn{5}{|c|}{ Metastatic recurrence } \\
\hline Yes & 9 & 6 & 3 & 0.045 \\
\hline No & 71 & 23 & 48 & \\
\hline \multicolumn{5}{|l|}{ Treatment } \\
\hline Radiotherapy & 42 & 16 & 26 & 0.720 \\
\hline Surgery+/-RT & 38 & 13 & 25 & \\
\hline
\end{tabular}

${ }^{1}$ Mann Whitney/Kruskal Wallis

(high expression), whereas 76 patients had tumors with low SERPINE1 expression. The rate of metastatic recurrences was significantly higher in the group of patients with tumors expressing high levels of SERPINE1 $(p=0.029)$, thus confirming the results obtained in the IHC analysis (Table 2). Alcohol consumption $(p=0.036)$ and local recurrence $(p=0.028)$ were also associated with SERPINE1 expression.

Patients with high SERPINE1 tumor expression had shorter LRFS $(p=0.022)$, PFS $(p=0.002)$ and CSS $(p=0.006)$ than patients with low SERPINE1 expression (Figure 2). Multivariate Cox model analysis showed that SERPINE1 expression (HR 1.73, 95\%CI 1.02-2.92, $p=0.042$ ), tumor size (HR 2.18, 95\% CI 1.29-3.70, $p=0.004)$ and node involvement (HR1.88, 95\%CI $1.13-3.16, p=0.016$ ) were independent risk factors for progression-free survival (Table 3). Moreover, tumor size (HR 1.78, 95\%CI 0.99-3.18, $p=0.050$ ) and node involvement (HR 2.23, 95\% CI 1.22-4.07, $p=0.009$ ) were identified as independent risk factors for survival (Table 3 ). There was a clear trend towards significance in the association between high SERPINE1 expression and poor patient survival (HR 1.78, 95\%CI 0.98-3.23, $p=0.057$ ), however the differences observed among groups, did not reach statistical significance in the multivariate analysis. Multivariate Cox analysis, excluding patients treated with surgery, showed that SERPINE1 expression (HR 1.92, $95 \%$ CI $1.03-3.59, p=0.043$ ) and tumor size (HR 2.39, $95 \%$ CI $1.29-4.39, p=0.005)$ were independent risk factors for progression-free survival in patients receiving radiotherapy and chemo-radiotherapy as the main treatment option (Table 3).

HPV status was analyzed in patients with oropharyngeal cancer treated at Hospital de la Santa Creu i Sant Pau (HSCSP). Thirty-five tumors were HPV negative, 9 HPV positive and HPV status was not available in 20 patients. SERPINE1 maintained its value as a marker of progression-free survival, when we analyzed the mRNA data from the prospective RT-PCR patient cohort, after excluding patients with oropharyngeal HPV positive tumors or oropharyngeal tumors which HPV status was unknown (Supplementary files, Figure S2). Patients with high SERPINE1 expression had a significantly progression-free survival than patients with low SERPINE1 expression $(p=0.015)$.

We analyzed SERPINE1 expression in a subgroup $(n=69)$ of patients included in the prospective study by immunohistochemistry. Again, SERPINE1 staining intensity was significantly associated with progressionfree survival (PFS) $(p=0.016)$ and cancer-specific survival (CSS) $(p=0.028)$, confirming the results obtained by RT-PCR (Figure 2E-2H).

\section{SERPINE1 expression was associated with poor survival in a third cohort of HNSCC patients included in The Cancer Genome Atlas database}

We analyzed SERPINE1 expression in an independent cohort of HNSCC patients having RNA sequencing results from 520 primary tumors and 44 mucosa samples recorded in The Cancer Genome Atlas (TCGA) database. SERPINE1 expression was significantly higher in tumor than in mucosa samples $(p<0.001)$ (Figure 3A). Kaplan -Meier curves showed that patients with high SERPINE1 tumor expression had shorter survival than patients with low SERPINE1 tumor expression $(p<0.001)$ (Figure 3B).

Univariate Cox model analysis showed that overall survival was significantly lower in patients whose tumors expressed high level of SERPINE1 than in patients with low SERPINE1 expression (HR:2.03, $95 \%$ CI $1.32-3.10, p=0.01)$. Multivariate Cox analysis showed that SERPINE1 expression (HR:1.73, 95\%CI $1.05-2.79, p=0.027)$ and pathologic $\mathrm{N}$ classification (HR:1.58, 95\%CI 1.09-2.31, $p=0.017$ ) were identified as independent risk factors for death in this HNSCC patient cohort (Table 4). Other clinical variables such as sex, tumor size and age were not associated with patient survival (Table 4). Differences in survival between high and or low expressing tumors remained statistically significant in an analysis of the TCGA patient cohort that excluded HPV positive tumors $(n=20)$. Patients with tumors showing a high expression of SERPINE1 continue to have a significantly $(p=0.001)$ higher risk of death than patients with low expression (Supplementary files, Figure S2). 
A Low SERPINE1 (1)

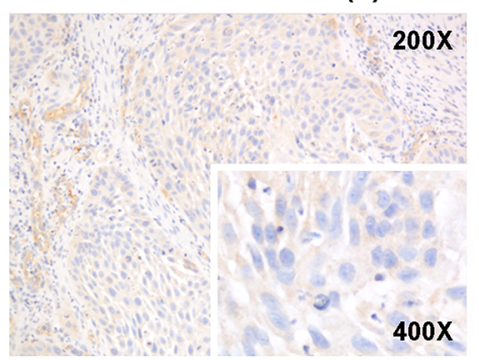

Intermediate SERPINE1 (2)

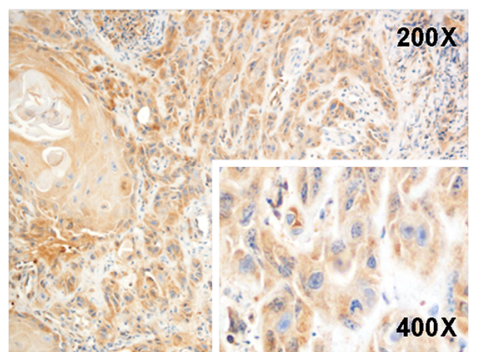

High SERPINE1 (3)

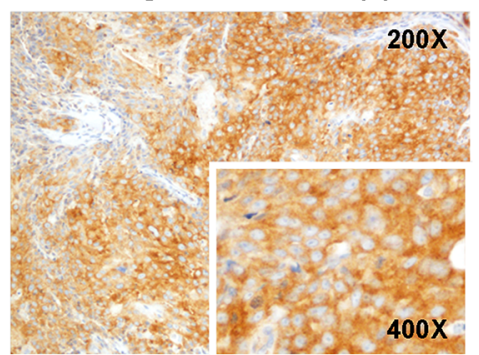

B
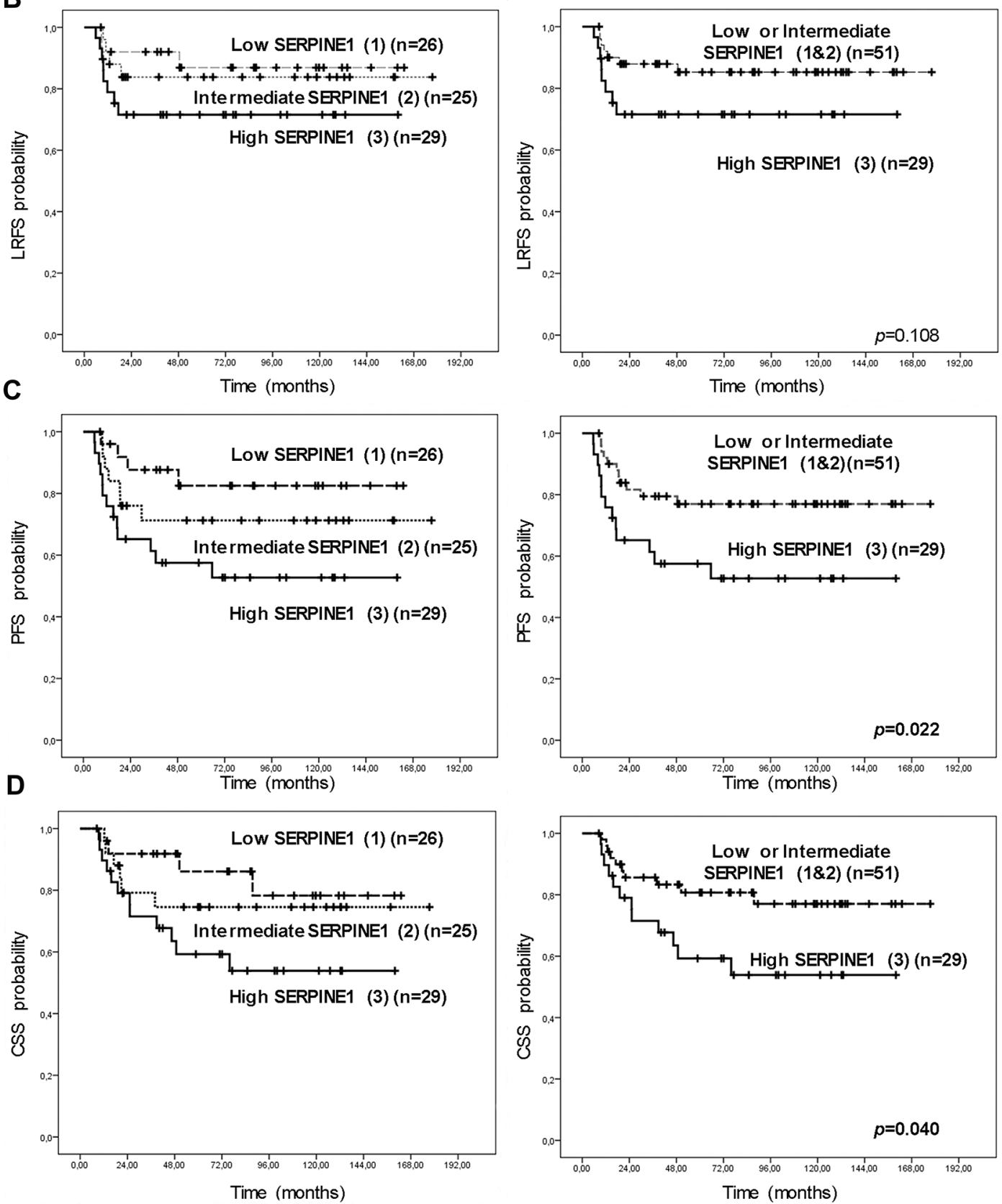

Figure 1: High protein SERPINE1 expression is associated with poor prognosis in patients with head and neck carcinoma included in a retrospective study. A. Representative images of SERPINE1 immunohistochemistry in pre-treatment tumor biopsies included in the retrospective study (low intensity, 1; intermediate intensity, 2; high intensity, 3). Differences in local recurrencefree (LRFS) B. progression-free (PFS) C. and cancer-specific (CSS) survival D. according to the intensity of SERPINE1 staining. 
Table 2: Characteristics of patients included in the prospective study

\begin{tabular}{|c|c|c|c|c|}
\hline Variable & $\begin{array}{l}\text { All patients } \\
(n=190)\end{array}$ & $\begin{array}{l}\text { High SERPINE1 } \\
\quad(n=114)\end{array}$ & $\begin{array}{c}\text { Low SERPINE1 } \\
(n=76)\end{array}$ & $P$ value $^{1}$ \\
\hline \multicolumn{5}{|l|}{ Sex } \\
\hline Men & 172 & 105 & 67 & 0.363 \\
\hline Women & 18 & 9 & 9 & \\
\hline \multicolumn{5}{|l|}{ Age (years) } \\
\hline$<60$ & 86 & 53 & 33 & 0.677 \\
\hline$>60$ & 104 & 61 & 43 & \\
\hline \multicolumn{5}{|l|}{ Tumor site } \\
\hline Oral cavity & 31 & 17 & 14 & 0.391 \\
\hline Oropharynx & 65 & 43 & 22 & \\
\hline Hypopharynx & 22 & 15 & 7 & \\
\hline Larynx & 62 & 39 & 33 & \\
\hline \multicolumn{5}{|l|}{ Tumor size (T) } \\
\hline $\mathrm{T} 1$ & 12 & 4 & 8 & 0.145 \\
\hline $\mathrm{T} 2$ & 60 & 34 & 26 & \\
\hline $\mathrm{T} 3$ & 73 & 45 & 28 & \\
\hline $\mathrm{T} 4$ & 45 & 31 & 14 & \\
\hline \multicolumn{5}{|l|}{ Node (n) } \\
\hline Positive & 111 & 73 & 38 & 0.054 \\
\hline Negative & 79 & 41 & 38 & \\
\hline \multicolumn{5}{|l|}{ Tumor differentiation } \\
\hline Well & 13 & 5 & 8 & 0.085 \\
\hline Moderate & 163 & 99 & 64 & \\
\hline Poor & 14 & 10 & 4 & \\
\hline \multicolumn{5}{|l|}{ Tobacco } \\
\hline Non-smoker & 14 & 7 & 7 & 0.687 \\
\hline$<20$ cigarette/day & 28 & 15 & 13 & \\
\hline$>20$ cigarette/day & 146 & 91 & 55 & \\
\hline Cigar or pipe & 2 & 1 & 1 & \\
\hline \multicolumn{5}{|l|}{ Alcohol } \\
\hline Non-drinker & 34 & 16 & 18 & 0.037 \\
\hline$<100$ gr./day & 81 & 45 & 36 & \\
\hline$>100$ gr./day & 75 & 53 & 22 & \\
\hline \multicolumn{5}{|l|}{ Local recurrence } \\
\hline Yes & 49 & 36 & 13 & 0.028 \\
\hline No & 141 & 78 & 63 & \\
\hline
\end{tabular}

(Continued) 


\begin{tabular}{|c|c|c|c|c|}
\hline Variable & $\begin{array}{l}\text { All patients } \\
(n=190)\end{array}$ & $\begin{array}{l}\text { High SERPINE1 } \\
\quad(n=114)\end{array}$ & $\begin{array}{l}\text { Low SERPINE1 } \\
\quad(n=76)\end{array}$ & $P$ value $^{1}$ \\
\hline \multicolumn{5}{|l|}{ Metastatic recurrence } \\
\hline Yes & 65 & 46 & 19 & 0.029 \\
\hline No & 125 & 68 & 57 & \\
\hline \multicolumn{5}{|l|}{ Treatment } \\
\hline Radiotherapy & 51 & 27 & 24 & 0.124 \\
\hline CDDP-based CRT & 74 & 52 & 22 & \\
\hline Cetux-based CRT & 6 & 4 & 2 & \\
\hline Surgery+/-RT & 59 & 31 & 28 & \\
\hline
\end{tabular}

${ }^{1}$ Mann Whitney/Kruskal Wallis

Interestingly, in the TCGA series, SERPINE1 expression was significantly associated with the presence of perineural invasion (PNI) $(p<0.001$, Fisher test). PNI-positive rate was higher in tumors with high SERPINE1 expression (54\%) than in tumors expressing low levels $(23.9 \%)$. The rate of lymphovascular invasion-positive tumors was higher in tumors with a high SERPINE1 expression (37\%) than in tumors with a low expression (28\%), however, differences between groups for this variable did not reach statistical significance $(p>0.05)$.

\section{SERPINE1 expression inhibits cell proliferation and enhances migration in head and neck carcinoma cell lines}

We analyzed SERPINE1 mRNA expression in six head and neck squamous cell carcinoma cell lines (UM-SCC-22A, UM-SCC-22B, UM-SCC-74B, FaDu, SCC9 and SCC25) (Figure 4A). The mean SERPINE1 mRNA level was 15.49 within a range of 1.00-69.24. The SCC9 cell line displayed the highest SERPINE1 expression whereas the rest of cell lines expressed similarly low SERPINE1 mRNA levels.

We next sought to determine whether the ectopic over-expression or inhibition of SERPINE1 could affect cell proliferation and migration. We generated a UM-SCC-74B cell line stably over-expressing SERPINE1 (74B-SerpE1up) by transducing it with the pFUGW_SERPINE1 lentiviral vector (Figure 4B). Transwell assays showed that SERPINE1 overexpression increased the migration capacity of the UM-SCC-74B cell line ( $p=0.004)$ (Figure 4C). Moreover, cell proliferation was reduced in cells overexpressing SERPINE1 at 72 hours $(p<0.01)$ and 96 hours after seeding $(p<0.01)$ (Figure 4D).

The SCC9 cell line was selected for SERPINE1 down-regulation using lentiviral transduction with two shRNA constructs (TRC2_331004, TRC2_370159). SCC9shRNA004 and SCC9shRNA159 transduced cells that stably expressed shRNA showed inhibition of SERPINE1 expression (Figure 5A). The Inhibition of SERPINE1 expression analyzed by RT-PCR was $65 \%$ for the SCC9shRNA004 and 75\% for the SCC9shRNA159 (Figure 5A).

After SERPINE1 inhibition, a partial loss of its characteristic fusiform shape was observed in the SCC9 cell line (Figure 5B). Inhibition of SERPINE1 expression by shRNA reduced migration in SCC9shRNA004 and SCC9shRNA159 transduced cells $(p<0.001$ and $p<0.001$, respectively) (Figure 5C). Cell proliferation was significantly higher in SCC9shRNA004 and SCC9shRNA159 cells than in the parental SCC9 cells at 48 hours, 72 hours and 96 hours after seeding (Figure 5D).

We analyzed the activation status of the PI3K/ AKT cell signaling pathway in cells over-expressing or under-expressing SERPINE1. The 74B-SerpE1up cells, which over-expressed SERPINE1, showed higher levels of AKT phosphorylation than the parental UM-SCC-74B cell line, whereas SCC9shRNA004 and SCC9shRNA159 transduced cells, that under-expressed SERPINE1, had lower levels of AKT phosphorylation than the SCC9 scramble cell line (Figure 5F). The treatment of 74BSerpE1up cells during 48 hours with a specific AKT inhibitor (MK-2206) reduced AKT phosphorylation (Figure 5G) and reverted the increased migration observed in cells over-expressing SERPINE1 (Figure $5 \mathrm{H}$ ). Moreover, after $48 \mathrm{~h}$ of exposure to $50 \mathrm{nM}$ PAI-039, a specific inhibitor of SERPINE1, we observed a downregulation of p-AKT in 74BSerpE1up cells overexpressing SERPINE1 (Figure 5I).

\section{Ectopic over-expression of SERPINE1 protects cells from cisplatin-induced apoptosis}

The 74B-SerpE1up cells, which over-expressed SERPINE1, were less sensitive to cisplatin treatment than UM-SCC-74B cells. After 48 hours of exposure to cisplatin, the IC50 increased from $10 \mu \mathrm{M}$ to $20 \mu \mathrm{M}$ by the ectopic expression of SERPINE1. We analyzed the 
A

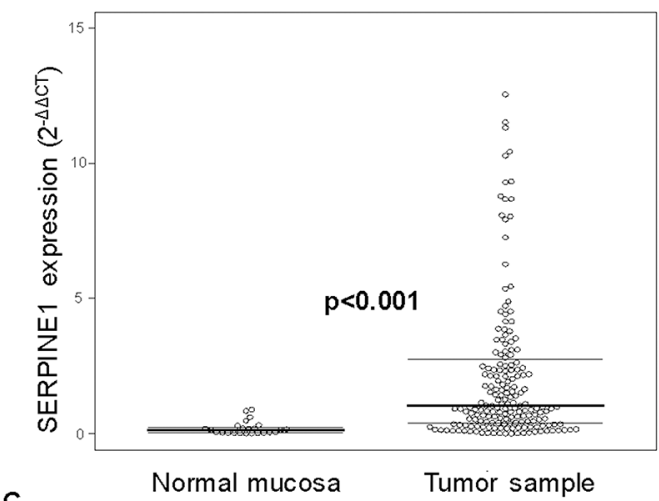

C

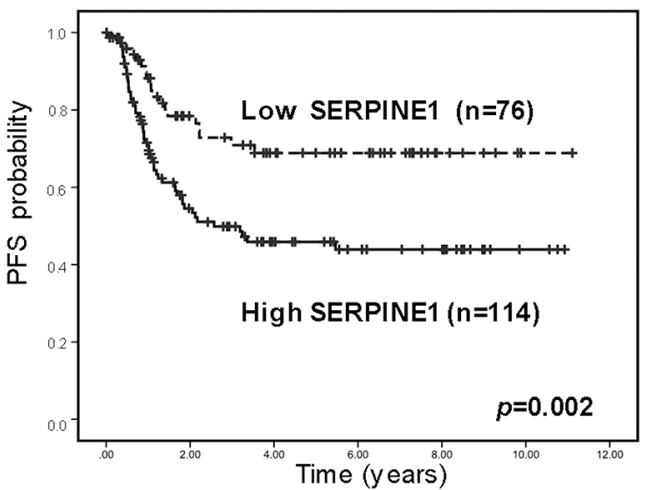

E

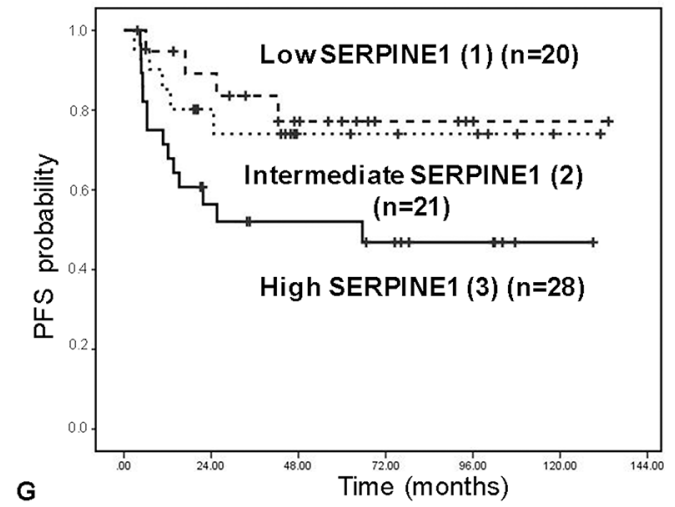

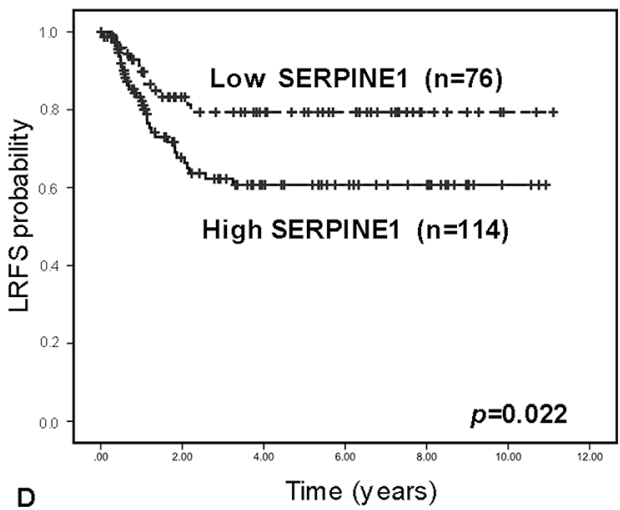

D

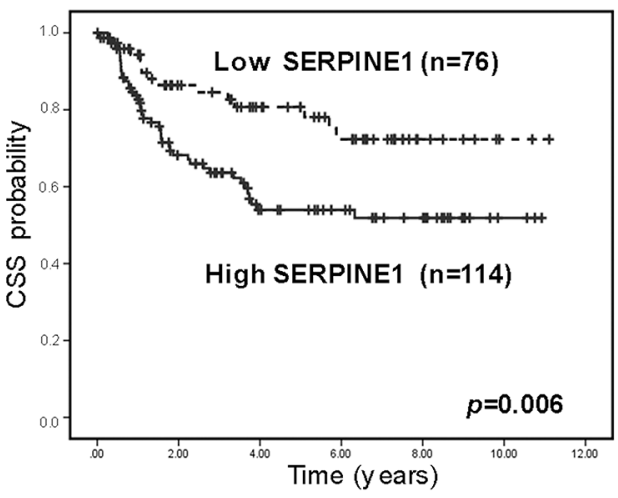

F
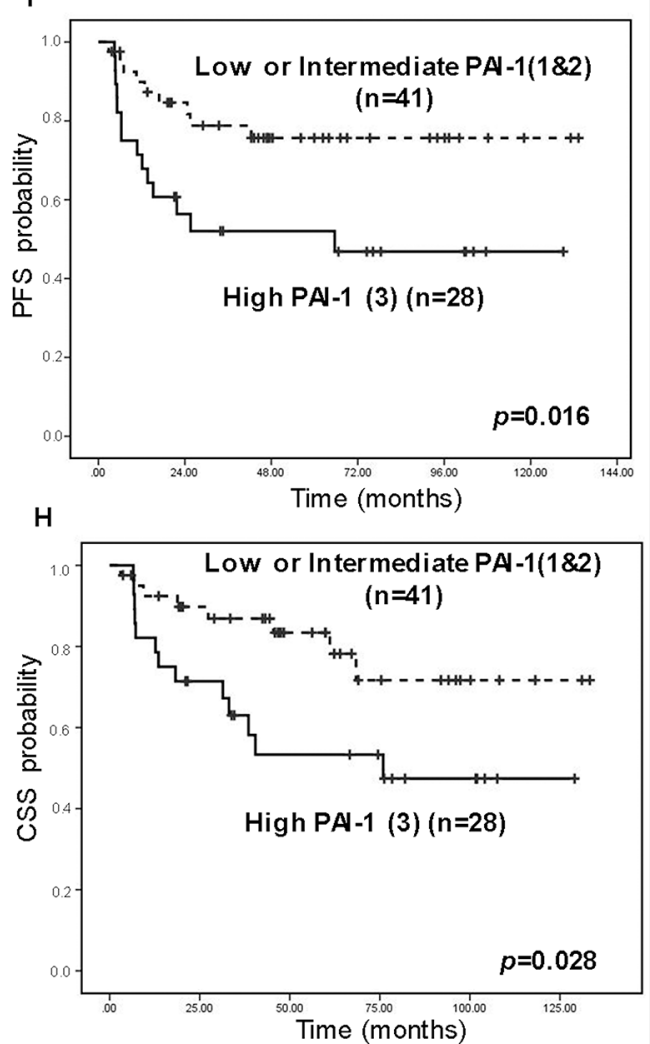

Figure 2: High SERPINE1 expression is associated with poor outcome in patients with head and neck carcinoma in a prospective study. A. Differences in SERPINE1 mRNA expression between normal mucosa and the evaluated tumor samples. Differences in local recurrence-free (LRFS) B. progression-free (PFS) C. and cancer-specific survival (CSS) D. according to SERPINE1 mRNA expression ( $n=190)$. Differences in progression-free (PFS) E-F. and cancer-specific (CSS) G-H. survival according to SERPINE1 immunostaining in 69 patients included in the prospective cohort. 
Table 3: Multivariate Cox model analysis in patients included in the prospective analysis $(n=190)$

All Patients $(n=190)$

\begin{tabular}{l|c|c|c|c|}
\hline \multicolumn{2}{c}{} & \multicolumn{2}{c}{ Progression- free survival (PFS) } & \multicolumn{2}{c}{ Cancer-specific survival (CSS) } \\
\hline Sex & HR (95\% CI) & p value & HR (95\% CI) & $p$ value \\
\hline Tumor size (T) & $1.02(0.39-2.61)$ & 0.976 & $1.76(0.72-4.30)$ & 0.217 \\
\hline Node (N) & $2.18(1.29-3.70)$ & $\mathbf{0 . 0 0 4}$ & $1.78(0.99-3.18)$ & $\mathbf{0 . 0 5 0}$ \\
\hline Age & $1.88(1.13-3.16)$ & $\mathbf{0 . 0 1 6}$ & $2.23(1.22-4.07)$ & $\mathbf{0 . 0 0 9}$ \\
\hline SERPINE1 & $0.86(0.54-1.37)$ & 0.514 & $0.767(0.46-1.29)$ & 0.320 \\
\hline \hline
\end{tabular}

Radiotherapy/Chemoradiotherapy treated $(n=131)$

\begin{tabular}{l|c|c|c|c|}
\hline & \multicolumn{2}{c}{ Progression- free survival (PFS) } & \multicolumn{1}{c}{ Cancer-specific survival (CSS) } \\
\hline \multicolumn{1}{r}{} & HR (95\% CI) & p value & HR value \\
\hline Sex & $1.13(0.39-3 . .29)$ & 0.976 & $1.76(0.58-5.30)$ & 0.317 \\
\hline Tumor size (T) & $2.39(1.29-4.39)$ & $\mathbf{0 . 0 0 5}$ & $1.95(0.97-3.89)$ & 0.059 \\
\hline Node (N) & $1.71(0.94-3.11)$ & 0.077 & $2.41(1.15-5.06)$ & $\mathbf{0 . 0 2 0}$ \\
\hline Age & $0.83(0.48-1.44)$ & 0.507 & $0.84(0.443-1.59)$ & 0.594 \\
\hline SERPINE1 & $1.92(1.03-3.59)$ & $\mathbf{0 . 0 4 3}$ & $1.80(0.86-3.78)$ & 0.117 \\
\hline
\end{tabular}

Sex = Male versus Female; Tumor size = T3-T4 versus T1-T2; Node $(\mathrm{N})=$ positive node versus negative node; Age: $<60$ years versus $>60$ years; SERPINE1 $=$ high versus low expression $\mathrm{HR}=$ Hazard Ratio; 95\% IC = 95\% Confidence Interval;

A

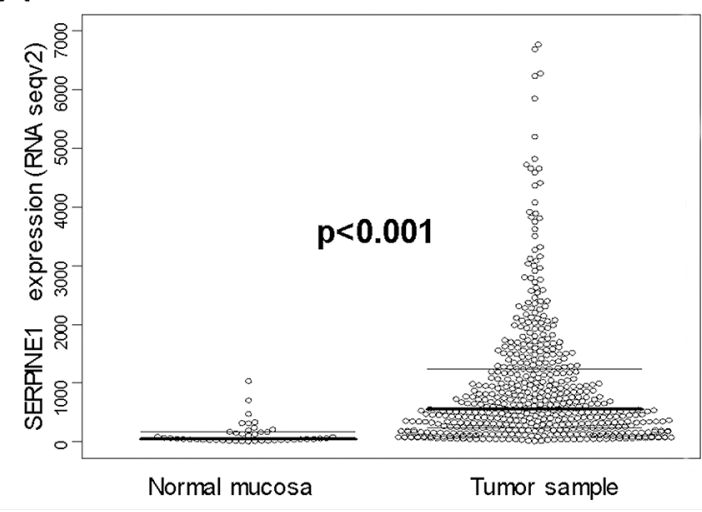

B

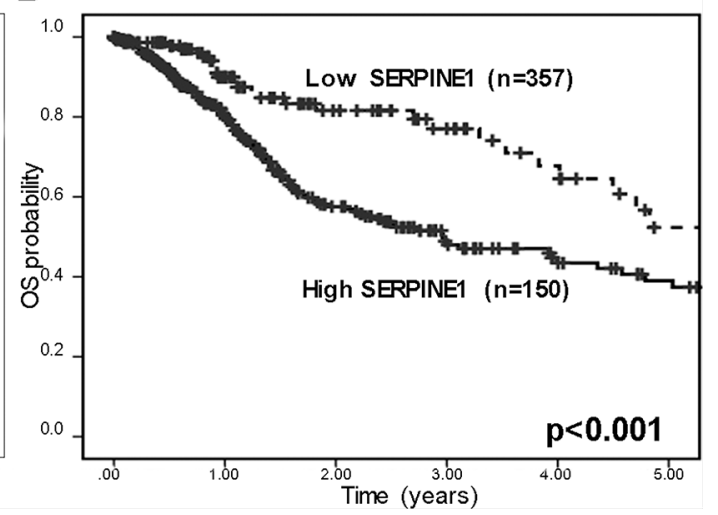

Figure 3: SERPINE1 expression in patients included in the Cancer Genome Atlas Database (TCGA). A. Differences in mRNA expression of SERPINE1 between normal mucosa $(n=44)$ and primary tumor samples $(n=520)$ of the HNSCC patients included in The Cancer Genome Atlas (TCGA) database. B. Differences in overall survival between patients, included in TCGA database, bearing tumors with low or high SERPINE1 tumor expression.

number of apoptotic bodies (nuclear condensation) in UM-SCC-74B and 74B-SerpE1up cells after 16 hours of cisplatin treatment. Cells over-expressing SERPINE1 (74B-SerpE1up) showed fewer apoptotic bodies than the parental UM-SCC-74B cells (Figure 4E). In line with these results, the inhibition of SERPINE1 expression in SCC9 cells significantly increased cisplatin-induced apoptosis. The number of apoptotic bodies after cisplatin exposure in the SCC9shRNA004 and SCC9shRNA159 transduced cells was higher than in SCC9 scramble cells (Figure 5E).
The number of apoptotic bodies observed after treatment with the combination of cisplatin ( $48 \mathrm{~h}$ exposure) with the AKT inhibitor MK2206 (72 h exposure), was significantly higher in the UM-SCC-74B or 74BSerpE1 up cells than in the corresponding cells treated with cisplatin alone (48 $\mathrm{h}$ exposure) (Figure 5J). The differences between groups were more intense in cells over-expressing SERPINE1 (74B-SerpE1up) in which the combination of cisplatin with the AKT inhibitor MK2206 completely reverted their resistance to apoptosis. 
Table 4: Multivariate Cox model analysis for overall survival in patients included in TCGA database $(n=507)$

\begin{tabular}{|l|c|c|c|c|}
\hline \multicolumn{2}{c}{ Cox Univariate } & \multicolumn{2}{c}{ Cox Multivariate } \\
\hline Sex & \multicolumn{1}{c}{ HR (95\% CI) } & $\boldsymbol{p}$ value & $1.09(0.73-1.64)$ & 0.665 \\
\hline Tumor size (T) & $1.23(0.88-1.71)$ & 0.225 & $1.25(0.81-1.92)$ & 0.311 \\
\hline Pathologic N & $1.22(0.87-1.71)$ & 0.233 & $1.58(1.09-2.31)$ & $\mathbf{0 . 0 1 7}$ \\
\hline Age & $1.62(1.11-2.35)$ & $\mathbf{0 . 0 1 2}$ & $1.31(0.89-1.93)$ & 0.169 \\
\hline SERPINE1 & $1.30(0.94-1.81)$ & 0.112 & $1.725(1.06-2.79)$ & $\mathbf{0 . 0 2 7}$ \\
\hline
\end{tabular}

Sex $=$ Male versus Female; Tumor size $=$ T3-T4 versus T1-T2; Pathologic $N=$ positive node versus negative node; Age: $>60$ years versus $<60$ years; SERPINE1 $=$ high versus low expression

$\mathrm{HR}=$ Hazard Ratio; 95\% IC = 95\% Confidence Interval.

The combination of cisplatin with the AKT inhibitor MK2206 completely reverts the resistance of 74BSerpE1 cells (overexpressing Serpine1) to cisplatin, since it induces apoptosis at a level similar to that achieved in UM-SCC-74B cells after their treatment with the same combination (Figure 5J).

\section{DISCUSSION}

We identified SERPINE1 expression as a poor prognostic marker in head and neck squamous cell carcinoma. A high expression of SERPINE1 increased the risk of metastasis and was associated with a poor clinical outcome.

We obtained these results analyzing two independent patient cohorts with head and neck cancer $(n=80, n=190)$. We used a third patient cohort of HNSCC $(n=507)$ included in TCGA database to support the association between SERPINE1 expression and patient survival. Despite using different methods to detect SERPINE1 expression in pre-treatment tumor biopsies, we observed a positive association between high SERPINE1 expression and poor clinical outcome in three independent patient cohorts. Taken together, our results show that SERPINE1 expression has a strong prognostic value in patients with head and neck carcinoma. We also identified SERPINE1 expression as an independent risk factor for tumor progression in patients treated with radiotherapy or chemo-radiotherapy.

We confirmed the prognostic value of SERPINE1 expression excluding HPV tumors from the survival analysis in the three patient cohorts. Therefore, the results of this study could be particularly relevant in HPV negative HNSCC population. Due to the low incidence of HPV positive tumors detected in our patient cohorts, which is a finding consistent with our geographical area [31], we could not assess whether SERPINE1 is or not a prognostic marker in HPV positive patients. Future studies in a large HNSCC patient cohort bearing HPV positive tumors will be needed to assess this possibility.
Evidence on the value of SERPINE1 expression as a prognostic factor in head and neck cancer has been inconclusive to date. In line with our results, Speleman and colleagues showed that high expression of SERPINE1 was associated with shorter disease-free survival in a univariate analysis performed in $46 \mathrm{HNSCC}$ patients [16]. Magnussen and colleagues identified SERPINE1 and UPAR expression as predictive markers of disease specific death in early stage oral carcinomas $(n=26)$ [26]. However, due to the relatively small number of patients analyzed and the lack of a multivariate analysis, these two studies did not reveal whether SERPINE1 could be used as an independent marker to predict the risk of disease relapse. Three further studies also found that SERPINE1 expression was associated with HNSCC prognosis but only when it was analyzed together with additional markers, such as uPA, SPARC or SMA [20, 27, 28]. In contrast, many other studies found no association between SERPINE1 and clinical outcome in HNSCC patients [15, $18,29,30]$. Our study may have helped towards resolving this controversy because it has identified SERPINE1 expression as a strong independent prognostic marker in patients with HNSCC.

Our results are consistent with those reported in other cancer types. SERPINE1 has been associated with poor clinical outcome in colon, breast, gastric, cervical, esophageal, lung, ovarian and thyroid cancers $[9,14$, 32-37]. Similarly to our findings in HNSCC, a high expression of SERPINE1 was found to increase the risk of developing metastasis in patients with node negative breast cancer.

We have shown that the ectopic over-expression of SERPINE1 promotes cell migration, whereas the inhibition of SERPINE1 expression generates the opposite effect, reducing the migration capacity of HNSCC cell lines. The observed association between high SERPINE1 expression and enhanced cell migration may seem counterintuitive regarding the notion that PA inhibition could reduce ECM degradation and cell invasion. However, previous studies have shown that SERPINE1 
A

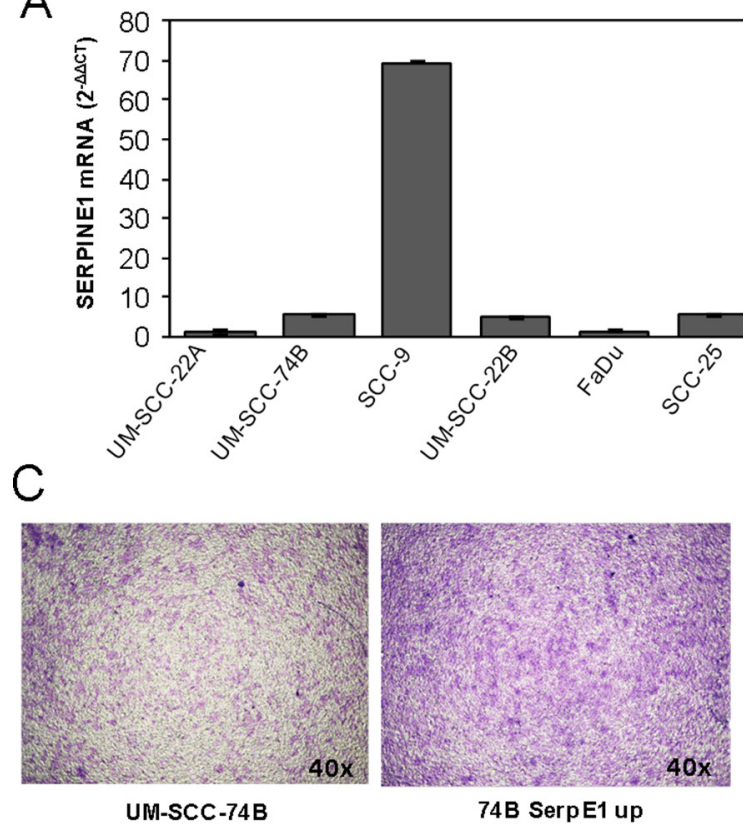

$\mathrm{E}$

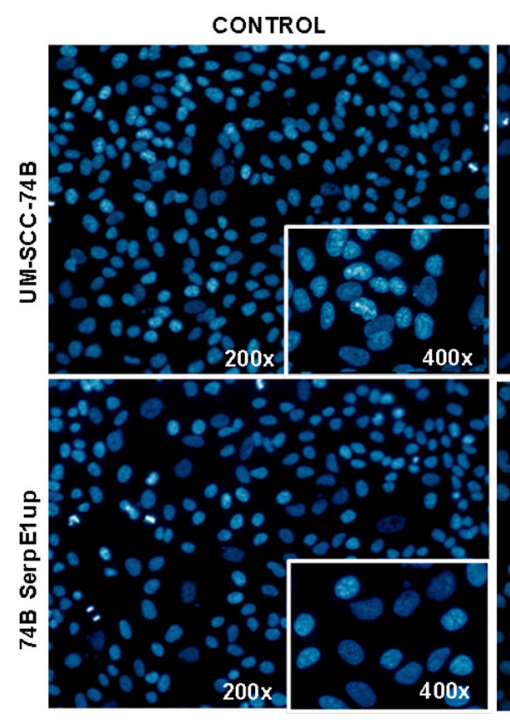

$B$
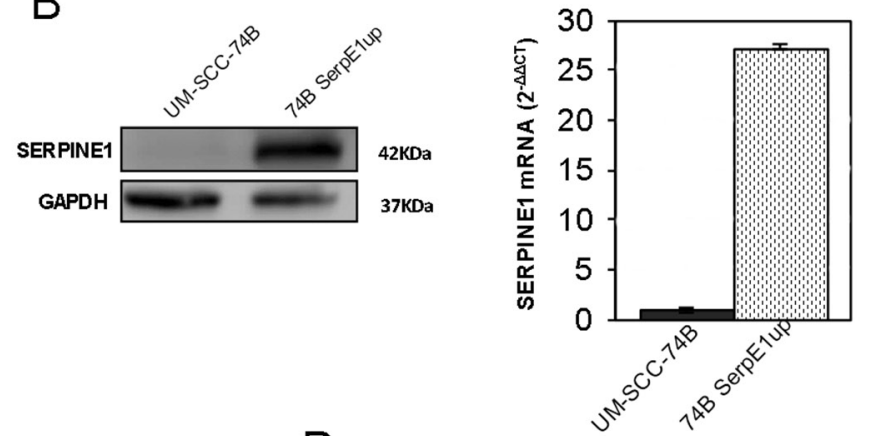

D
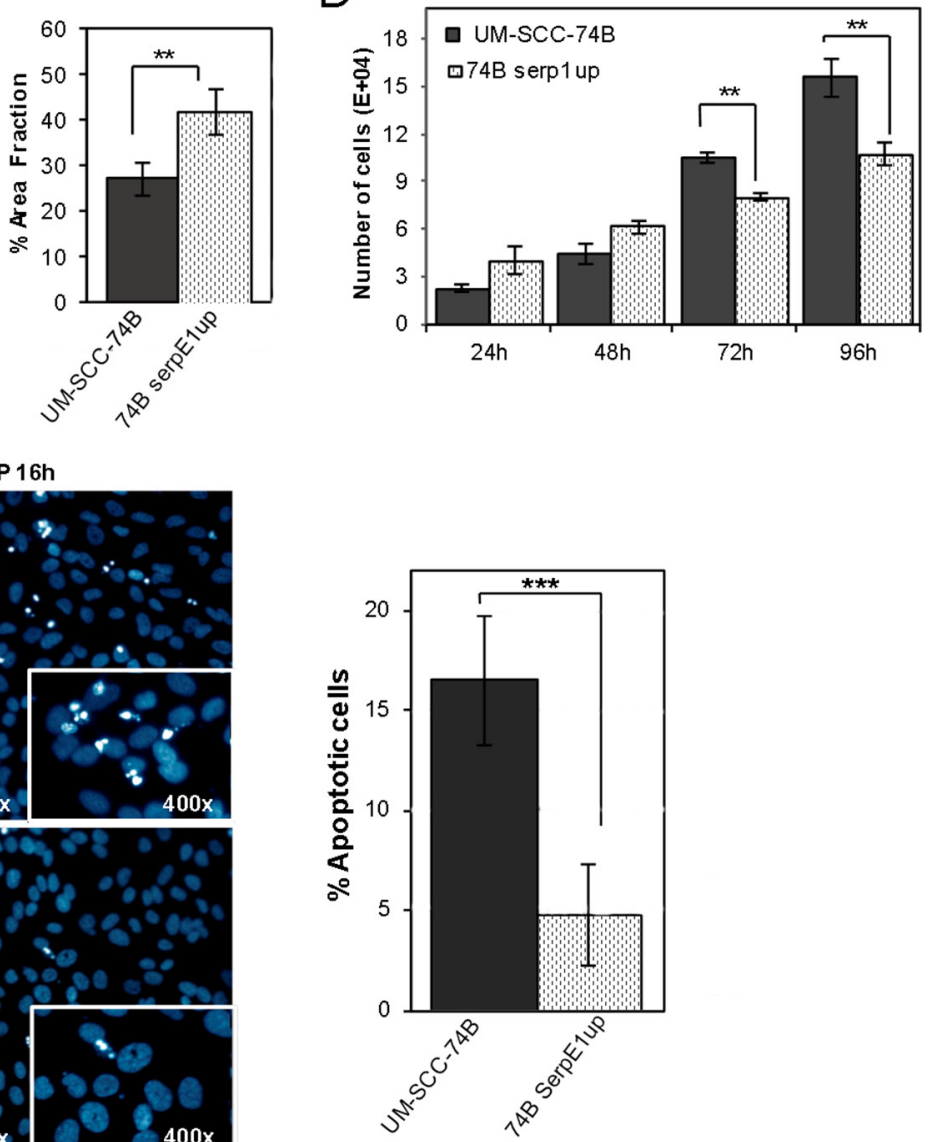

Figure 4: Ectopic over-expression of SERPINE1 increases migration, reduces proliferation and inhibits apoptotic induction in the UM-SCC-74B HNSCC cell line. A. SERPINE1 mRNA levels in six HNSCC cell lines. B. SERPINE1 overexpression in the stably transduced UM-SCC-74B cell line (74B-SerpE1up), as analyzed by Western-Blot (left) and RT-PCR (right). Transwell migration C. and cell proliferation D. assays in UM-SCC-74B and 74B-PAIl up cells. E. Representative images of DAPI stained nuclei in UM-SCC-74B and 74B-SerpElup cells before and after 16 hours of $15 \mu \mathrm{M}$ cisplatin treatment (left) Over-expression of SERPINE1 reduces the number of apoptotic figures in cisplatin-treated cells (right). ${ }^{* *} p<0.01$ and ${ }^{* * *} p<0.001$.

promotes cell migration through its inhibitory activity against plasmin, preserving the stromal architecture and providing traction for cancer cells during migration [38]. Furthermore, SERPINE1 can also improve cell migration by a mechanism independent of the fibrinolytic pathway [39-41]. In vitro results, showing that SERPINE1 overexpression increases migration in head and neck tumor cells, are in agreement with the higher risk of metastatic recurrence observed in patients bearing tumors with a high expression of SERPINE1. They are also consistent with perineural invasion being more frequent in tumors overexpressing SERPINE1 in the TGCA cohort, which also support the role of this protein in head and neck tumor dissemination.

We also showed that cells over-expressing SERPINE1 were less sensitive to cisplatin treatment; one of the main drugs included in most chemotherapy protocols for the treatment of HNSCC patients. Interestingly, we observed an activation of the AKT pathway in cells over-expressing SERPINE1 that could 
A

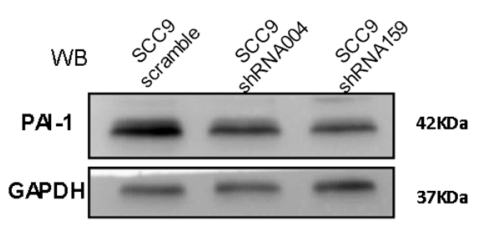

RT-PCR

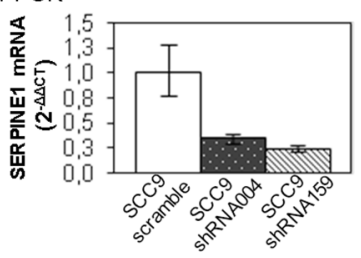

D

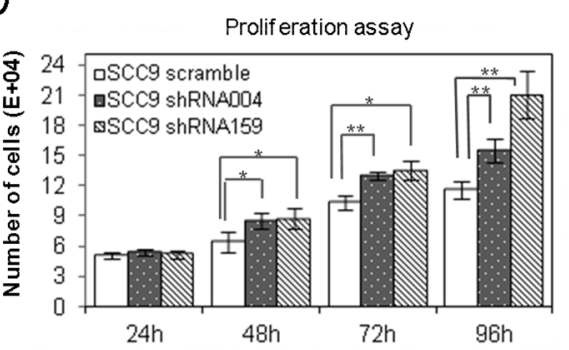

E
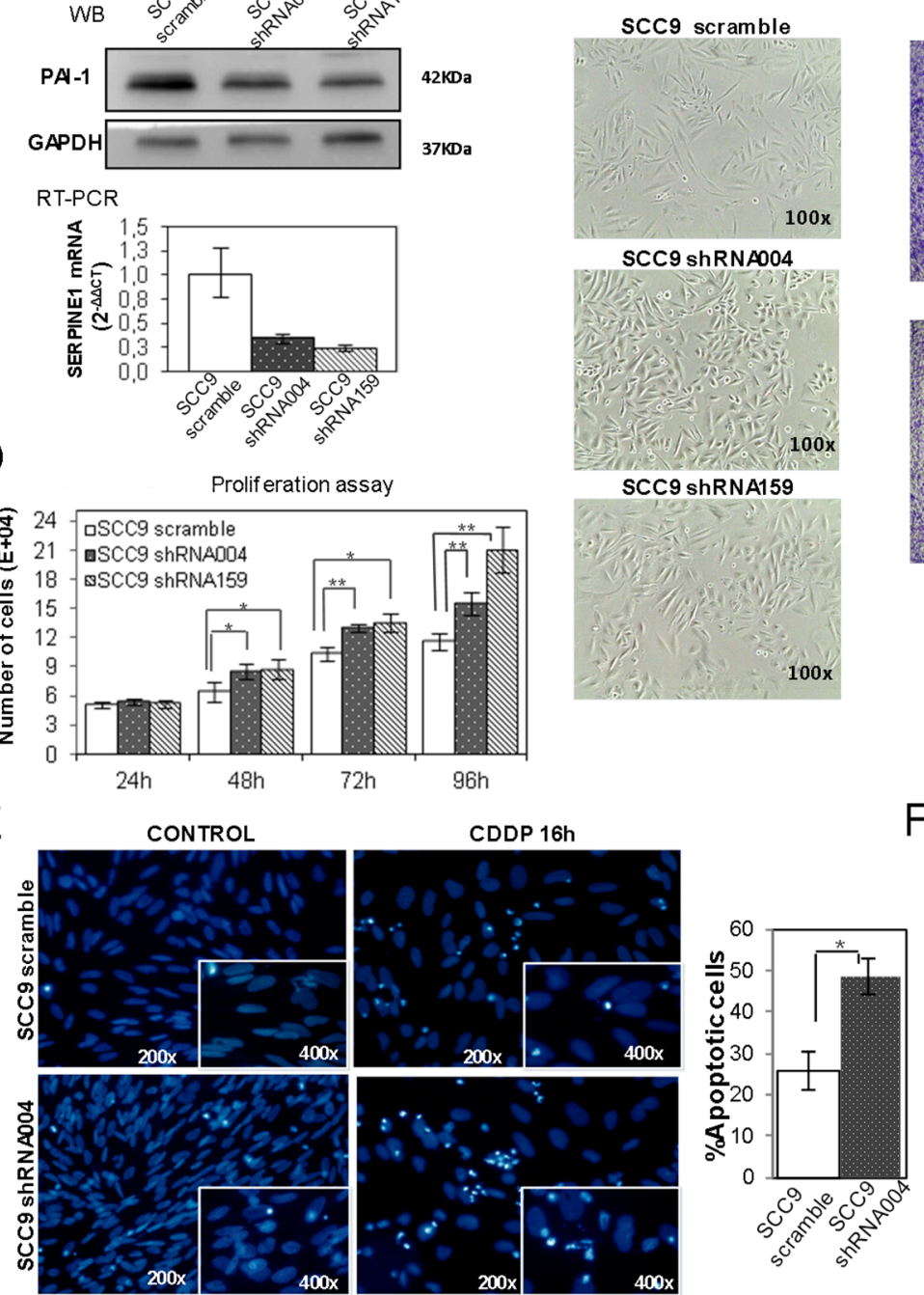

SCC9 ShRNA004

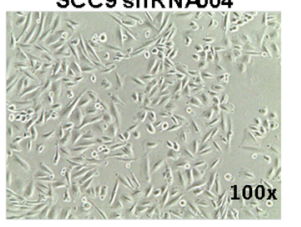

SCC9 ShRNA159

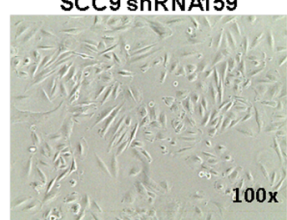

$100 x$

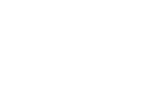

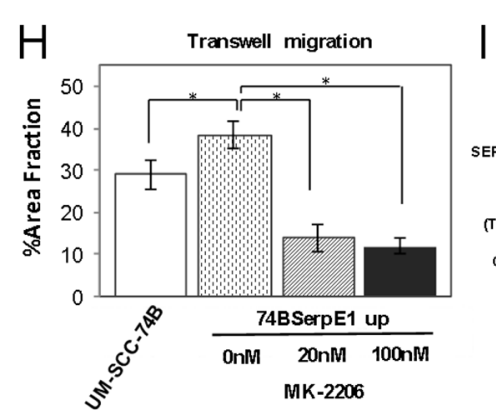
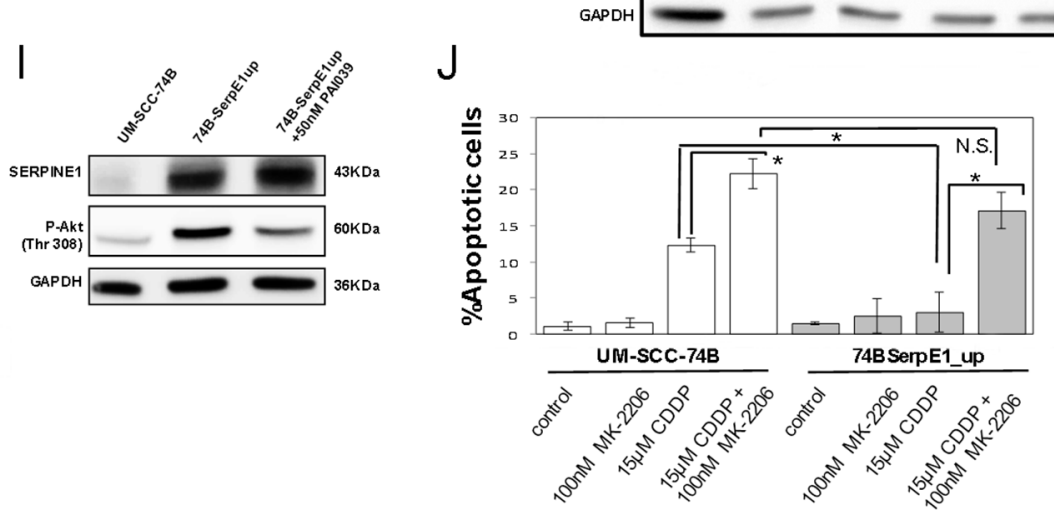

Figure 5: PAI-1 knockdown in the SCC9 cell line decreases migration, enhances proliferation and promotes apoptotic induction. A. Expression of SERPINE1 in SCC9 and cells transduced with shRNAi (SCC9 shRNA004 and SCC9 shRNA159, as assessed by Western-Blot (above) or RT-PCR (bellow); B. Representative images showing changes in cell morphology after the inhibition of SERPINE1 expression; C. Transwell migration and D. proliferation assays in SCC9, SCC9 shRNA004 and SCC9 shRNA159 cells; E. Representative images of DAPI stained nuclei before and after 16 hours of $40 \mu \mathrm{M}$ cisplatin treatment in SCC9 and shRNA transduced cells, showing higher apoptosis in PAI-1 downregulated cells; F. Western blot analysis of P-Akt, PI3K and ERK in SCC9, SCC9 shRNA004, UM-SCC-74B and 74BSerplup cells; G. western blot analysis of P-Akt in cells treated during 48 hours with the AKT inhibitor MK-2206; H. Transwell migration assays in cells treated with the MK-2206 inhibitor; I. SERPINE1 and P-Akt protein expression in cells treated 48 hours with the SERPINE1 inhibitor PAI-039. J. Combination of cisplatin and AKT inhibitor MK2206 in UM-SCC-74B and 74BSerpE1 up cells. ${ }^{*} p<0.05$ 
be responsible for the stimulation of cell migration and the protection of HNSCC cells from cisplatin-induced apoptosis. Similar findings have been reported in breast carcinoma, human promyeolocityc leukemia, prostate carcinoma and fibrosarcoma cells. In these tumor types a high expression of SERPINE1 protects cells from chemotherapy-induced apoptosis and associates with the activation of the PI3K/AKT/mTOR signaling pathway [42-44]. Consistently, activation of this pathway is emerging as an important oncogenic mechanism in HNSCC [45] and has been associated with an increase in tumor cell motility and survival signaling [46-48].

Although the inhibition of cell proliferation in cells displaying high SERPINE1 expression may at first glance seem inconsistent with its oncogenic role, previous studies have pointed out that the enhanced migration induced by SERPINE1 expression may also be accompanied by a decrease in cell proliferation $[49,50]$. It is reasonable to assume that changes in cell morphology necessary for cell motility and migration (e.g. cytoskeleton reorganization) are incompatible with those required for cell proliferation and division [51-55]. In line with the results obtained in head and neck cancer cells, SERPINE1 has also been described as a key player in wound healing and tissue remodeling programs by inhibiting cell proliferation and promoting epithelial cell migration [49]. Regional or distant metastases are the most common cause of death in patients with HNSCC. However, little is known about the mechanisms underlying their development. Our results suggest that SERPINE1 expression could be up-regulated during tumor cell transformation and this could result in an increase in the capacity of tumor cells to migrate, generate metastasis and develop resistance to genotoxic therapy and this is likely to have a negative impact on tumor response and patient clinical outcome. In the future, SERPINE1 expression could be included, together with other molecular and clinical variables, in diagnostic and therapeutic algorithms to predict clinical outcome in HNSCC patients. SERPINE1 could help to improve patient stratification and to develop personalized therapeutic approaches, thereby improving patient quality of life and survival. Just as SERPINE1 expression is being used to guide the administration of adjuvant chemotherapy in patients with node-negative breast cancer, in HNSCC patients it could be useful to help decide whether to intensify or de-intensify treatment according to their risk of recurrence. SERPINE1 levels could also be used to define the group of patients who should have a close clinical follow-up in order to anticipate the development of metastatic recurrences. Despite the positive association between SERPINE1 expression and poor clinical outcome observed in three independent cohorts, larger multicenter studies and clinical trials are warranted, using one of the pre-established cut-offs and techniques here described, to replicate our findings. This could validate SERPINE1 as a new biomarker useful for making treatment decisions in head and neck carcinoma patients.

In summary, a high expression of SERPINE1 is a poor prognostic marker in head and neck squamous cell carcinoma patients that increases the risk of metastatic recurrences after therapy, possibly due to an increase in tumor cell migration and in resistance to cisplatin.

\section{MATERIALS AND METHODS}

\section{Patient characteristics, tissue samples and clinical follow-up}

This study was performed analyzing two independent cohorts of patients with pathologically confirmed HNSCC. A retrospective study $(n=80)$ was performed using formallin-fixed paraffin-embedded (FFPE) pre-treatment tumor biopsies from patients at advanced stage (III, IVa and IVb) treated between 1995 and 2003 at Hospital de la Santa Creu i Sant Pau (HSCSP), Barcelona.

A second prospective study $(n=190)$ was run using fresh tumor biopsies obtained from patients treated at HSCSP $(n=167)$ and at Hospital Moises Broggi $(n=23)$, Sant Joan Despí, Barcelona, from 2002 to 2012. Twenty-four fresh mucosa samples were obtained from HNSCC patients in areas without visible lesions. Fresh samples were frozen in RNAlater (Life Technologies Ltd, UK) and kept in liquid nitrogen until processing and until de RT-PCR analyses. Tumor samples with $<80 \%$ of tumor tissue were excluded from the prospective study. Sixty-nine FFPE biopsies from patients included in this cohort were used to confirm SERPINE1 by immunohistochemistry. The study was approved by the local Ethics Committee and the Institutional Review Board at HSCSP, and informed consent was obtained from each patient. The study was conducted in accordance with REMARK guidelines and the declaration of Helsinki (Supplementary files, table S1) [56]. The median followup time was 68 months in the retrospective study and 37 months in the prospective study.

Local recurrence-free survival (LRFS) was defined as time from treatment initiation to recurrence at the primary site. Progression free-survival (PFS) was the time elapsed between treatment initiation and tumor progression. Tumor progression was considered as an increase in tumor size of $25 \%$ or higher, or the appearance of new lesions (local or regional recurrences, and distant metastases). Cancer-specific survival (CSS) was defined as time from diagnosis to death from cancer.

HPV status, detected using the short PCRfragment-10 (SPF-10) assay (Lab. Biomedical Products, Rijswik, the Nederland's), was available for oropharyngeal tumors treated at HSCSP. A single patient with a HPV positive tumor was included in the retrospective study. 
In the prospective study, thirty-five tumors were HPV negative, $9 \mathrm{HPV}$ positive and HPV status was not available in 20 patients.

We also analyzed SERPINE1 mRNA levels in 520 primary tumor samples and 44 normal mucosas obtained from HNSCC patients included in The Cancer Genome Atlas (TCGA) database (https://tcga-data.nci.nih.gov/ tcga/). To analyze SERPINE1 expression in this cohort we used level 3 RNASeqv2 normalized expression values. Survival data were available for 507 patients.

\section{Immunohistochemistry}

5- $\mu \mathrm{m}$ tissue block sections were deparaffinized in xylol and rehydrated using decreasing ethanol concentrations $(100 \%, 96 \%, 80 \%, 70 \%$, and $50 \%)$. For antigenic retrieval, samples were immersed in target retrieval solution, $\mathrm{pH} 9$ (Dako, USA) and autoclaved for 10 minutes at $121^{\circ} \mathrm{C}$. Endogenous tissue peroxidase was inactivated by immersing the samples in a $3 \% \mathrm{H}_{2} \mathrm{O}_{2}$ solution for 10 minutes Samples were incubated with SERPINE1 monoclonal antibody (clone 1D5; Abnova, Taiwan) at 1:200 dilution. The EnVision ${ }^{\mathrm{TM}}$ FLEX and FLEX + Visualization System was used for primary antibody detection following standard procedures. Two head and neck surgical samples and SCC9 cells overexpressing SERPINE1 were used as positive controls whereas negative controls were processed substituting the primary antibody by non-immunized mouse serum (Supplementary files, Figure S1). Immunostained sections were quantified by two independent observers using a Olympus BX51 microscope.

The percentage of positive cells $(0-100 \%)$ and the overall intensity of staining (1, no staining or weak; 2, moderate; and 3, strong) were established analyzing five randomly choosen microscopic fields at $100 x$ magnification for each sample. SERPINE1 expression was only evaluated in tumor cells.

There was inter-observer agreement in 95\% of the samples; the remaining slides were re-evaluated and consensus decisions were made. Images were acquired using an Olympus DP72 digital camera and processed with CellD Imaging 3.3 software (Olympus).

\section{RNA purification and RT-PCR}

RNA was isolated using Trizol reagent (Life Technologies Ltd, Paisley, UK) as previously described [57]. cDNA synthesis was performed using $1.5 \mu \mathrm{g}$ of total RNA, $5 \mu \mathrm{L}$ of RT buffer, $2 \mu \mathrm{L}$ of dNTPs mixture, $5 \mu \mathrm{L}$ of Random Hexamer Primers, $125 \mathrm{U}$ of MultiScribe Reverse Transcriptase and $40 \mathrm{U}$ of RNase inhibitor (Life Technologies Ltd, Paisley, UK), in a $50 \mu \mathrm{L}$ final reaction volume with the High Capacity cDNA Archive Kit (Life Technologies Ltd, UK). Reaction conditions were $25^{\circ} \mathrm{C}$ for 20 minutes, $37^{\circ} \mathrm{C}$ for 2 hours and $95 \mathrm{C}$ for
3 minutes. Real Time RT-PCR reactions were performed in duplicate using the Hs01126607_m1 gene expression assay (Life Technologies Ltd, UK). HPRT1 amplification (Hs99999909_m1) was used as an endogenous control and RNA obtained from the UM-SCC-22A cell line was used as the calibration sample. Gene expression levels were expressed as fold change relative to the calibration sample (UM-SCC-22A), applying the comparative CT method $\left(2^{\# x 2212 ; \Delta \Delta C T}\right)$. For UM-SCC-22A, RNA extraction and cDNA synthesis were performed following the same steps as described for tumor samples.

\section{Cell culture}

SERPINE1 expression and proliferation, migration and apoptosis assays were performed using six human head and neck squamous cell carcinoma cell lines (UM-SCC-22A, UM-SCC-22B, UM-SCC-74B, SCC9, $\mathrm{SCC} 25$ and $\mathrm{FaDu}$ ). $293 \mathrm{~T}$ cells were only used to generate lentivirus-containing supernatants.

UM-SCC-22A, UM-SCC-22B, UM-SCC-74B [58] and 293T (ATCC ${ }^{\circledR}$ CRL-3216 ${ }^{\mathrm{TM}}$; ATCC; http://www. lgcstandards-atcc.org) cell lines were grown in Dulbecco's modified Eagle's medium (DMEM) containing 10\% FBS, $100 \mathrm{U} / \mathrm{mL}$ streptomycin / penicillin and $2 \mathrm{mM}$ glutamine (Life Technologies Ltd, UK). SCC-9 (ATCC ${ }^{\circledR}$ CRL-1629'9) and SCC-25 (ATCC ${ }^{\circledR}$ CRL-1628 ${ }^{\mathrm{TM}}$ ) HNSCC cell lines were grown in DMEM/F12 (1:1) containing $10 \% \mathrm{FBS}, 100 \mathrm{U} / \mathrm{mL}$ streptomycin/penicillin, $2 \mathrm{mM}$ glutamine and $0.4 \mu \mathrm{g} / \mathrm{mL}$ of hydrocortisone. FaDu (ATCC ${ }^{\circledR}$ HTB-43 ${ }^{\mathrm{TM}}$ ) HNSCC cell line from ATCC was grown in Dulbecco's modified Eagle's medium (DMEM) containing 10\% FBS, $100 \mathrm{U} / \mathrm{mL}$ streptomycin/penicillin and $2 \mathrm{mM}$ glutamine. All cell lines were cultured in a humidified atmosphere at $37^{\circ} \mathrm{C}$ and $5 \%$ of $\mathrm{CO}_{2}$. Cell lines were authenticated comparing the STR profiles obtained using the Cell ID kit (Promega Corporation, Madison, WI) with the original STR profiles previously described (Supplementary files, table S2) [58, 59].

\section{Generation of SERPINE1 over-expressing cell lines}

cDNA-encoding human SERPINE1 was obtained from a pcDNA3.1-SERPINE1 plasmid (generously gift from Paul J. Higgins) and subcloned into the XhoIBamHI site of the lentiviral vector FUtdTW obtained from Addgene (http://www.addgene.org/) [60, 61]. Lentiviral packaging was achieved after cotransfection of the vector plasmid with pMD.G_VSV G-poly-A vector and p8 91-Gag-Pol vector into $293 \mathrm{~T}$ cells using lipofectamine 2000 kit (Life Technologies Ltd, UK). The lentivirus-containing supernatant was harvested 48 hours after 293T transfection, filtered through a $45 \mu \mathrm{m}$ filter (Millipore) and stored at $-80^{\circ} \mathrm{C}$. UM-SCC-74B cells were transduced with the SERPINE1-expressing lentiviral 
vector (pFUGW_SERPINE1) and stable SERPINE1 overexpressing cells were selected exposing cells to $500 \mu \mathrm{g} /$ $\mathrm{mL}$ zeocin for four weeks.

\section{Generation of SERPINE1 knockdown cell lines}

Lentiviral vectors (pLKO.1-puro) containing short hairpin RNA (shRNA) against human SERPINE1 (TRC2_331004, TRC2_370159) and non-mammalian shRNA control plasmid DNA (scramble) were purchased from Sigma-Aldrich (Sigma Aldrich, MO, USA). Lentiviral packaging and transduction of SCC9 cells were performed as described for SERPINE1 over-expression. Stable SERPINE1 knockdown cells were selected in $10 \mu \mathrm{g} / \mathrm{mL}$ puromycin (Life Technologies Ltd, Paisley, UK). After four weeks of antibiotic selection, SERPINE1 expression was determined by Real Time PCR and Western blot.

\section{Proliferation, migration, cytotoxicity and apoptosis assays}

Proliferation assays were performed seeding cells in the range of $3.5 \times 10^{4}$ cells/well (UM-SCC-74B and vector-transduced cells) to $7 \times 10^{4}$ cells $/$ well (SCC9 and shRNA-transduced cells) in six-well plates. Cells were harvested after $24 \mathrm{~h}, 48 \mathrm{~h}, 72 \mathrm{~h}$ and $96 \mathrm{~h}$ of growth and counted using a Countess ${ }^{\circledR}$ automated cell counter (Life Technologies Ltd, UK).

For the migration assays, cells were pre-incubated for 24 hours in FBS-free medium and seeded onto the upper chamber of a transwell cell culture insert diameter $6.5 \mathrm{~mm}$, pore size $8 \mu \mathrm{m}$ ) (Corning, USA) in the presence of FBS-free medium. Each insert was introduced into a well (12-well plate) containing $500 \mu \mathrm{L}$ of medium with FBS. After 24 hours incubation, cells at the top of the upper transwell chamber were removed by a mechanical action with gauze swabs and the external cells at the bottom of the transwell chamber were fixed for 10 minutes in methanol, stained with crystal violet for 10 minutes and dried at $37^{\circ} \mathrm{C}$. Images were captured using the DP73 Olympus digital camera (Olympus Corporation, Japan). The extent of migration was determined by the area fraction occupied by cells in five $\times 100$ fields using CellSens dimension v1.9 software (Olympus Corporation, Japan). Experiments were performed in triplicate and repeated three times.

For cytotoxicity assays, cells seeded in 96 well/ plates $(2500$ cells/well), were exposed to cisplatin at a concentration ranging from 2.5 to $80 \mu \mathrm{M}$ for 48 hours. We determined drug sensitivity measuring cell metabolic capacity using the XTT Cell proliferation kit II, as previously described (Roche Diagnostics, Germany) [62]. The half maximal inhibitory concentration (IC50) was calculated by linear interpolation as previously described [62].
To determine cisplatin-induced apoptosis, we treated cells with $15-40 \mu \mathrm{M}$ cisplatin for 16 hours. After treatment, cells were fixed for 1 minute in methanol at $-20^{\circ} \mathrm{C}$ and stained with ProLong ${ }^{\circledR}$ Gold Antifade DAPI (Life Technologies Ltd, Paisley, UK). Apoptotic and non-apoptotic nuclei were counted under a fluorescence microscope. We determined the mean percentage of apoptotic bodies assessing six 200X images per sample. MK-2206 (Selleckchem, Houston, TX, USA) and PAI-039 (Axon Medchem BV, Netherlands) inhibitors were used to study the AKT pathway activation.

\section{Western blot}

Cell protein extracts and western blot analysis were performed as previously described [63]. Briefly, $75 \mu \mathrm{g}$ of cellular protein extract was electrophoretically-separated and transferred to nitrocellulose membranes over-night. Membranes were blocked in TBS-T buffer $[0.132 \mathrm{~m} \mathrm{NaCl}$, $0.02 \mathrm{~m}$ Tris (pH7.5), $0.1 \%$ Tween 20] containing $5 \mathrm{~g} / 100 \mathrm{ml}$ of milk for 1.5 hours and incubated over-night with primary antibodies. Dilutions for the primary antibodies were: SERPINE1(1:1000, MAB10390, Abnova, USA), PhosphoAkt (Thr308)(1:1000, \#9275, Cell Signalling), Akt (1:500, Mouse anti-Akt clone 55, BD Biosciences), ERK(1:2500, clone 16/ERK, BD Biosciences, USA), PI3K (1:2500, clone 4/PI3-Kinase, BD Biosciences) and GAPDH (1:10000, MAB374, Merck Millipore, Germany).

\section{Statistical analysis}

In the RT-PCR analysis and the TCGA database, the cut off to distinguish patients with high SERPINE1 expression and patients with low SERPINE1 expression was determined using Classification and Regression Tree Analysis (CART) [64]. CART analysis selected the cutoff with the best sensitivity and specificity to distinguish patients with a high risk of disease relapse from patients with low risk according to PA-1 expression.

Mann-Whitney and Kruskal-Wallis tests were used to assess the association between sex, age, tumor site, tumor size, node status, tumor differentiation, tobacco and alcohol consumption, rate of recurrences, with SERPINE1 expression. We distinguished between local (same anatomic site for recurrence and primary tumor) and metastatic (node recurrences or distant metastasis) recurrences. Kaplan-Meier analysis and Log-Rank test were used to analyze differences in LRFS, PFS and CSS between the subgroups of patients established according to SERPINE1 expression. A multivariate Cox model was used to test the association between sex, tumor size, node involvement, age or SERPINE1 mRNA expression with PFS and CSS. To analyze differences between two or more conditions in "in vitro" assays, we used the non-parametric Mann-Whitney U or Kruskal-Wallis tests. 
Statistical analyses were performed using the SPSS v.22 (IBM Corporation, Armonk, NY) software. Differences were considered significant at $p$-values $<0.05$ in all the applied tests.

\section{ACKNOWLEDGMENTS}

We would like to thank Luis Carlos Navas for technical support, Carolyn Newey for help with the English and the ORL groups of HSCSP and HMB for their collaboration in biopsy sampling. We also thank the patients who gave consent to use their tissue for research.

\section{CONFLICTS OF INTEREST}

The authors declare no conflicts of interest

\section{GRANT SUPPORT}

Financial support: Grants SGR1437 (AGAUR) and CB06/01/1031 (CIBER-BBN) and PI12/01861 (Plan Estatal de I+D+I 2013-2016 of the Instituto de Salud Carlos III, co-funding from FEDER) to RM; Grants PI11/00525 (Instituto de Salut Carlos III) and Ayudas Merck Serono 2011 (Fundación Salud 2000) to AB; Grant PI14/01918 (Plan Estatal de I+D+I 2013-2016 of the Instituto de Salud Carlos III, co-funding from FEDER) to XL. Marta Tellez-Gabriel and Irene Arroyo are fellows of AGAUR.

\section{REFERENCES}

1. Leemans CR, Braakhuis BJ, Brakenhoff RH. The molecular biology of head and neck cancer. Nat Rev Cancer. 2011; 11:9-22.

2. Siegel R, Ma J, Zou Z, Jemal A. Cancer statistics. CA Cancer J Clin. 2014; 64:9-29.

3. Argiris A, Karamouzis MV, Raben D, Ferris RL. Head and neck cancer. Lancet. 2008; 371:1695-1709.

4. Leon X, Quer M, Diez S, Orus C, Lopez-Pousa A, Burgues J. Second neoplasm in patients with head and neck cancer. Head Neck. 1999; 21:204-210.

5. Braakhuis BJ, Brakenhoff RH, Leemans CR. Treatment choice for locally advanced head and neck cancers on the basis of risk factors: biological risk factors. Ann Oncol. 2012; 23:x173-177.

6. Lu P, Takai K, Weaver VM, Werb Z. Extracellular matrix degradation and remodeling in development and disease. Cold Spring Harb Perspect Biol. 2011; 3.

7. Frantz C, Stewart KM, Weaver VM. The extracellular matrix at a glance. J Cell Sci. 2010; 123:4195-4200.

8. Kwaan HC, McMahon B. The role of plasminogen-plasmin system in cancer. Cancer Treat Res. 2009; 148:43-66.
9. Ulisse S, Baldini E, Sorrenti S, D'Armiento M. The urokinase plasminogen activator system: a target for anti-cancer therapy. Curr Cancer Drug Targets. 2009; 9:32-71.

10. Mazar AP. Urokinase plasminogen activator receptor choreographs multiple ligand interactions: implications for tumor progression and therapy. Clin Cancer Res. 2008; 14:5649-5655.

11. Margheri F, Luciani C, Taddei ML, Giannoni E, Laurenzana A, Biagioni A, Chilla A, Chiarugi P, Fibbi G, Del Rosso M. The receptor for urokinase-plasminogen activator (uPAR) controls plasticity of cancer cell movement in mesenchymal and amoeboid migration style. Oncotarget. 2014; 5:1538-1553.

12. Duffy MJ, McGowan PM, Gallagher WM. Cancer invasion and metastasis: changing views. J Pathol. 2008; 214:283-293.

13. Harris L, Fritsche H, Mennel R, Norton L, Ravdin P, Taube S, Somerfield MR, Hayes DF, Bast RC Jr. American Society of Clinical Oncology update of recommendations for the use of tumor markers in breast cancer. J Clin Oncol. 2007; 25:5287-5312.

14. Look MP, van Putten WL, Duffy MJ, Harbeck N, Christensen IJ, Thomssen C, Kates R, Spyratos F, Ferno M, Eppenberger-Castori S, Sweep CG, Ulm K, Peyrat JP, Martin PM, Magdelenat H, Brunner N, et al. Pooled analysis of prognostic impact of urokinase-type plasminogen activator and its inhibitor PAI-1 in 8377 breast cancer patients. J Natl Cancer Inst. 2002; 94:116-128.

15. Strojan P, Budihna M, Smid L, Vrhovec I, Skrk J. Urokinase-type plasminogen activator (uPA) and plasminogen activator inhibitor type 1 (PAI-1) in tissue and serum of head and neck squamous cell carcinoma patients. Eur J Cancer. 1998; 34:1193-1197.

16. Speleman L, Kerrebijn JD, Look MP, Meeuwis CA, Foekens JA, Berns EM. Prognostic value of plasminogen activator inhibitor-1 in head and neck squamous cell carcinoma. Head Neck. 2007; 29:341-350.

17. Lindberg P, Larsson A, Nielsen BS. Expression of plasminogen activator inhibitor-1, urokinase receptor and laminin gamma-2 chain is an early coordinated event in incipient oral squamous cell carcinoma. Int J Cancer. 2006; 118:2948-2956.

18. Huang CF, Yu GT, Wang WM, Liu B, Sun ZJ. Prognostic and predictive values of SPP1, PAI and caveolin-1 in patients with oral squamous cell carcinoma. Int J Clin Exp Pathol. 2014; 7:6032-6039.

19. Shi Z, Stack MS. Urinary-type plasminogen activator (uPA) and its receptor ( $\mathrm{UPAR}$ ) in squamous cell carcinoma of the oral cavity. Biochem J. 2007; 407:153-159.

20. Chin D, Boyle GM, Williams RM, Ferguson K, Pandeya N, Pedley J, Campbell CM, Theile DR, Parsons PG, Coman WB. Novel markers for poor prognosis in head and neck cancer. Int J Cancer. 2005; 113:789-797. 
21. Chen YJ, Lin SC, Kao T, Chang CS, Hong PS, Shieh TM, Chang KW. Genome-wide profiling of oral squamous cell carcinoma. J Pathol. 2004; 204:326-332.

22. Liu CJ, Liu TY, Kuo LT, Cheng HW, Chu TH, Chang KW, Lin SC. Differential gene expression signature between primary and metastatic head and neck squamous cell carcinoma. J Pathol. 2008; 214:489-497.

23. Mendez E, Houck JR, Doody DR, Fan W, Lohavanichbutr P, Rue TC, Yueh B, Futran ND, Upton MP, Farwell DG, Heagerty PJ, Zhao LP, Schwartz SM, Chen C. A genetic expression profile associated with oral cancer identifies a group of patients at high risk of poor survival. Clin Cancer Res. 2009; 15:1353-1361.

24. Roepman P, Wessels LF, Kettelarij N, Kemmeren P, Miles AJ, Lijnzaad P, Tilanus MG, Koole R, Hordijk GJ, van der Vliet PC, Reinders MJ, Slootweg PJ, Holstege FC. An expression profile for diagnosis of lymph node metastases from primary head and neck squamous cell carcinomas. Nat Genet. 2005; 37:182-186.

25. Schmalbach CE, Chepeha DB, Giordano TJ, Rubin MA, Teknos TN, Bradford CR, Wolf GT, Kuick R, Misek DE, Trask DK, Hanash S. Molecular profiling and the identification of genes associated with metastatic oral cavity/pharynx squamous cell carcinoma. Arch Otolaryngol Head Neck Surg. 2004; 130:295-302.

26. Magnussen S, Rikardsen OG, Hadler-Olsen E, Uhlin-Hansen L, Steigen SE, Svineng G. Urokinase plasminogen activator receptor ( $\mathrm{UPAR}$ ) and plasminogen activator inhibitor-1 (PAI-1) are potential predictive biomarkers in early stage oral squamous cell carcinomas (OSCC). PLoS One. 2014; 9:e101895.

27. Dhanda J, Triantafyllou A, Liloglou T, Kalirai H, Lloyd B, Hanlon R, Shaw RJ, Sibson DR, Risk JM. SERPINE1 and SMA expression at the invasive front predict extracapsular spread and survival in oral squamous cell carcinoma. Br J Cancer. 2014.

28. Hundsdorfer B, Zeilhofer HF, Bock KP, Dettmar P, Schmitt M, Kolk A, Pautke C, Horch HH. Tumourassociated urokinase-type plasminogen activator (uPA) and its inhibitor PAI-1 in normal and neoplastic tissues of patients with squamous cell cancer of the oral cavity clinical relevance and prognostic value. J Craniomaxillofac Surg. 2005; 33:191-196.

29. Nozaki S, Endo Y, Kawashiri S, Nakagawa K, Yamamoto E, Yonemura Y, Sasaki T. Immunohistochemical localization of a urokinase-type plasminogen activator system in squamous cell carcinoma of the oral cavity: association with mode of invasion and lymph node metastasis. Oral Oncol. 1998; 34:58-62.

30. Strojan P, Budihna M, Smid L, Vrhovec I, Skrk J. Urokinase-type plasminogen activator, plasminogen activator inhibitor type 1 and cathepsin D: analysis of their prognostic significance in squamous cell carcinoma of the head and neck. Anticancer Res. 2000; 20:3975-3981.
31. Rodrigo JP, Heideman DA, Garcia-Pedrero JM, Fresno MF, Brakenhoff RH, Diaz Molina JP, Snijders PJ, Hermsen MA. Time trends in the prevalence of HPV in oropharyngeal squamous cell carcinomas in northern Spain (1990-2009). Int J Cancer. 2014; 134:487-492.

32. Sakakibara T, Hibi K, Koike M, Fujiwara M, Kodera Y, Ito K, Nakao A. Plasminogen activator inhibitor-1 as a potential marker for the malignancy of colorectal cancer. Br J Cancer. 2005; 93:799-803.

33. Duffy MJ, Maguire TM, McDermott EW, O'Higgins N. Urokinase plasminogen activator: a prognostic marker in multiple types of cancer. J Surg Oncol. 1999; 71:130-135.

34. Harbeck N, Alt U, Berger U, Kruger A, Thomssen C, Janicke F, Hofler H, Kates RE, Schmitt M. Prognostic impact of proteolytic factors (urokinase-type plasminogen activator, plasminogen activator inhibitor 1 , and cathepsins $\mathrm{B}, \mathrm{D}$, and L) in primary breast cancer reflects effects of adjuvant systemic therapy. Clin Cancer Res. 2001; 7:2757-2764.

35. Duffy MJ. Urokinase plasminogen activator and its inhibitor, PAI-1, as prognostic markers in breast cancer: from pilot to level 1 evidence studies. Clin Chem. 2002; 48:1194-1197.

36. Rotblat B, Grunewald TG, Leprivier G, Melino G, Knight RA. Anti-oxidative stress response genes: bioinformatic analysis of their expression and relevance in multiple cancers. Oncotarget. 2013; 4:2577-2590.

37. Langlois B, Saupe F, Rupp T, Arnold C, van der Heyden M, Orend G, Hussenet T. AngioMatrix, a signature of the tumor angiogenic switch-specific matrisome, correlates with poor prognosis for glioma and colorectal cancer patients. Oncotarget. 2014; 5:10529-10545.

38. Wilkins-Port CE, Ye Q, Mazurkiewicz JE, Higgins PJ. TGF-beta1 + EGF-initiated invasive potential in transformed human keratinocytes is coupled to a plasmin/MMP10/MMP-1-dependent collagen remodeling axis: role for PAI-1. Cancer Res. 2009; 69:4081-4091.

39. Czekay RP, Wilkins-Port CE, Higgins SP, Freytag J, Overstreet JM, Klein RM, Higgins CE, Samarakoon R, Higgins PJ. PAI-1: An Integrator of Cell Signaling and Migration. Int J Cell Biol. 2011; 2011:562481.

40. Degryse B, Neels JG, Czekay RP, Aertgeerts K, Kamikubo Y, Loskutoff DJ. The low density lipoprotein receptor-related protein is a motogenic receptor for plasminogen activator inhibitor-1. J Biol Chem. 2004; 279:22595-22604.

41. Kamikubo Y, Neels JG, Degryse B. Vitronectin inhibits plasminogen activator inhibitor-1-induced signalling and chemotaxis by blocking plasminogen activator inhibitor-1 binding to the low-density lipoprotein receptor-related protein. Int J Biochem Cell Biol. 2009; 41:578-585.

42. Romer MU, Larsen L, Offenberg $\mathrm{H}$, Brunner $\mathrm{N}$, Lademann UA. Plasminogen activator inhibitor 1 protects fibrosarcoma cells from etoposide-induced apoptosis 
through activation of the PI3K/Akt cell survival pathway. Neoplasia. 2008; 10:1083-1091.

43. Kwaan HC, Wang J, Svoboda K, Declerck PJ. Plasminogen activator inhibitor 1 may promote tumour growth through inhibition of apoptosis. Br J Cancer. 2000; 82:1702-1708.

44. Wolff C, Malinowsky K, Berg D, Schragner K, Schuster T, Walch A, Bronger H, Hofler H, Becker KF. Signalling networks associated with urokinase-type plasminogen activator (UPA) and its inhibitor PAI-1 in breast cancer tissues: new insights from protein microarray analysis. J Pathol. 2011; 223:54-63.

45. Martin D, Abba MC, Molinolo AA, Vitale-Cross L, Wang Z, Zaida M, Delic NC, Samuels Y, Lyons JG, Gutkind JS. The head and neck cancer cell oncogenome: a platform for the development of precision molecular therapies. Oncotarget. 2014; 5:8906-8923.

46. Xue G, Hemmings BA. PKB/Akt-dependent regulation of cell motility. J Natl Cancer Inst. 2013; 105:393-404.

47. Fang H, Placencio VR, DeClerck YA. Protumorigenic activity of plasminogen activator inhibitor-1 through an antiapoptotic function. J Natl Cancer Inst. 2012; 104:1470-1484.

48. Ju X, Katiyar S, Wang C, Liu M, Jiao X, Li S, Zhou J, Turner J, Lisanti MP, Russell RG, Mueller SC, Ojeifo J, Chen WS, Hay N, Pestell RG. Akt1 governs breast cancer progression in vivo. Proc Natl Acad Sci U S A. 2007; 104:7438-7443.

49. Simone TM, Higgins CE, Czekay RP, Law BK, Higgins SP, Archambeault J, Kutz SM, Higgins PJ. SERPINE1: A Molecular Switch in the Proliferation-Migration Dichotomy in Wound-“Activated" Keratinocytes. Adv Wound Care (New Rochelle). 2014; 3:281-290.

50. Lamb R, Lisanti MP, Clarke RB, Landberg G. Co-ordination of cell cycle, migration and stem cell-like activity in breast cancer. Oncotarget. 2014; 5:7833-7842.

51. Shiwarski DJ, Shao C, Bill A, Kim J, Xiao D, Bertrand CA, Seethala RS, Sano D, Myers JN, Ha P, Grandis J, Gaither LA, Puthenveedu MA, Duvvuri U. To "Grow" or "Go": TMEM16A Expression as a Switch between Tumor Growth and Metastasis in SCCHN. Clin Cancer Res. 2014; 20:4673-4688.

52. Giese A, Bjerkvig R, Berens ME, Westphal M. Cost of migration: invasion of malignant gliomas and implications for treatment. J Clin Oncol. 2003; 21:1624-1636.

53. Schultz C, Lemke N, Ge S, Golembieski WA, Rempel SA. Secreted protein acidic and rich in cysteine promotes glioma invasion and delays tumor growth in vivo. Cancer Res. 2002; 62:6270-6277.

54. Wang SD, Rath P, Lal B, Richard JP, Li Y, Goodwin CR, Laterra J, Xia S. EphB2 receptor controls proliferation/ migration dichotomy of glioblastoma by interacting with focal adhesion kinase. Oncogene. 2012; 31:5132-5143.

55. Fedotov S, Iomin A. Migration and proliferation dichotomy in tumor-cell invasion. Phys Rev Lett. 2007; 98:118101.

56. McShane LM, Altman DG, Sauerbrei W, Taube SE, Gion M, Clark GM. Reporting recommendations for tumor marker prognostic studies (REMARK). J Natl Cancer Inst. 2005; 97:1180-1184.

57. Pavon MA, Parreno M, Leon X, Sancho FJ, Cespedes MV, Casanova I, Lopez-Pousa A, Mangues MA, Quer M, Barnadas A, Mangues R. Ku70 predicts response and primary tumor recurrence after therapy in locally advanced head and neck cancer. Int J Cancer. 2008; 123:1068-1079.

58. Brenner JC, Graham MP, Kumar B, Saunders LM, Kupfer R, Lyons RH, Bradford CR, Carey TE. Genotyping of 73 UM-SCC head and neck squamous cell carcinoma cell lines. Head Neck. 2010; 32:417-426.

59. Zhao M, Sano D, Pickering CR, Jasser SA, Henderson YC, Clayman GL, Sturgis EM, Ow TJ, Lotan R, Carey TE, Sacks PG, Grandis JR, Sidransky D, Heldin NE, Myers JN. Assembly and initial characterization of a panel of 85 genomically validated cell lines from diverse head and neck tumor sites. Clin Cancer Res. 2011; 17:7248-7264.

60. Providence KM, Higgins SP, Mullen A, Battista A, Samarakoon R, Higgins CE, Wilkins-Port CE, Higgins PJ. SERPINE1 (PAI-1) is deposited into keratinocyte migration "trails" and required for optimal monolayer wound repair. Arch Dermatol Res. 2008; 300:303-310.

61. Rompani SB, Cepko CL. Retinal progenitor cells can produce restricted subsets of horizontal cells. Proc Natl Acad Sci U S A. 2008; 105:192-197.

62. Bosch R, Dieguez-Gonzalez R, Cespedes MV, Parreno M, Pavon MA, Granena A, Sierra J, Mangues R, Casanova I. A novel inhibitor of focal adhesion signaling induces caspaseindependent cell death in diffuse large B-cell lymphoma. Blood. 2011; 118:4411-4420.

63. Guerrero S, Casanova I, Farre L, Mazo A, Capella G, Mangues R. K-ras codon 12 mutation induces higher level of resistance to apoptosis and predisposition to anchorage-independent growth than codon 13 mutation or proto-oncogene overexpression. Cancer Res. 2000; 60:6750-6756.

64. Tellez-Gabriel M, Arroyo-Solera I, Leon X, Gallardo A, Lopez M, Cespedes MV, Casanova I, Lopez-Pousa A, Quer M, Mangues MA, Barnadas A, Mangues R, Pavon MA. High RAB5 expression is associated with good clinical outcome in patients with locally advanced head and neck squamous cell carcinoma. Cancer Med. 2013; 2:950-963. 